\title{
An Intracranial Leiomyosarcoma in a Child with Neurofibromatosis Type 1
}

\author{
Sumit Jhas, Lowell Henriques, Cynthia Hawkins, Eric Bouffet, James T. Rutka
}

Can. J. Neurol. Sci. 2009; 36: 491-495

Neurofibromatosis is a hereditary disorder characterized by widespread abnormalities in the nervous system, skin and bones. Neurofibromatosis type 1 (NF1 or von Recklinghausen's disease) is the most common form, with an incidence of $1 / 3500^{1}$. Neurofibromatosis type 1 is a disorder with variable phenotypic expression. Some patients may primarily have cutaneous expression, while others may have life-threatening or severely disfiguring complications. The variability in phenotypic expression of this disease is even demonstrated within families. The NF1 gene is located on chromosome 17 and encodes the tumor suppressor gene neurofibromin, a negative regulator of the Ras signaling pathway ${ }^{2}$. Inactivation of neurofibromin leads to cell proliferation and tumor development.

Neurofibromatosis type 1 is associated with both benign and malignant tumours. The most characteristic tumour in NF1 is the neurofibroma, a nerve sheath tumour composed of schwann cells, fibroblasts, mast cells and vascular components ${ }^{3}$. The risk of malignancy is three-five times greater in NF1 patients than in the general population ${ }^{4}$. About $30 \%$ of the mortality associated with NF1 is due to a malignancy of some kind. Some of the malignancies associated with NF1 include pheochromocytoma, leukemia, melanoma, carcinoid, Wilm's tumour and soft tissue sarcomas such as rhabdomyosarcoma and fibrosarcoma. Peripheral nervous system (PNS) tumors such as the plexiform neurofibroma and the malignant peripheral nerve sheath tumour are far more common than central nervous system (CNS) tumours in NF1 patients, but the latter can lead to significant mortality and morbidity. Approximately $90 \%$ of the CNS tumours associated with NF1 are pilocytic astrocytomas, the majority of which are optic pathway gliomas ${ }^{1,5,6}$. In addition to the pilocytic astrocytoma, NF1 patients may develop high grade astrocytic neoplasms. It is estimated that $15 \%$ of pediatric NF1 patients will have a brain neoplasm of one kind or another, a statistic that is similar to the adult population?

Since NF1 is a known tumour suppressor gene, its inactivation through a variety of different mechanisms could lead to tumorigenesis including malignant transformation. As such, there are numerous case reports demonstrating the association of NF1 and tumour formation. Some of these tumours, however, may occur with the same frequency in NF patients as they do in the general population. It is therefore important to differentiate these tumours in NF patients from those that are truly associated with NF1 where the incidence in the NF1 population is greater than that of the general population. The present case report depicts a child with NF1 in whom a tumour normally associated with NF1, a leiomyosarcoma, was diagnosed in the intracranial compartment. To our knowledge, this is the first intracranial leiomyosarcoma reported in a child with NF1. Previously described leiomyosarcomas in the NF1 patient have been predominantly abdominal in location.

\section{CASE Report}

A 14-year-old boy with a known history of NF1 and prior treatment for optic glioma presented with a two day history of severe headaches and vomiting that suddenly occurred while he was swimming. At age four, he had undergone craniotomy with debulking of a large, low grade chiasmatic glioma causing visual failure. Postoperatively he underwent cycles of chemotherapy with carboplatin and vincristine until he developed carboplatin allergy. He then received three cycles of vincristine and etoposide. Recurrent tumor and radiological progression was documented three years later, and he received weekly vinblastine for one year. Following this chemotherapy regimen, he experienced further progression and was treated with temozolomide for 16 months. The child's tumor was stable off chemotherapy for two years prior to his presentation on this occasion.

In the emergency room, his neurological exam was unremarkable except for his being legally blind from his optic glioma, and a mild left pronator drift. Computed tomogram (CT) followed by magnetic resonance image (MRI) revealed a right temporal intracerebral hemorrhage with midline shift remote from the chiasmatic tumor (Figure 1A-B). No vascular malformations or aneurysms were seen, but a nodular lesion in the superior temporal gyrus which enhanced with contrast administration could be seen. On the second day after admission, he developed a generalized, tonic-clonic seizure with a decreasing level of consciousness. He was taken to surgery emergently at which a right fronto-temporal craniotomy was performed, and the temporal hematoma was evacuated. Intraoperatively, the child became hemodynamically unstable from blood loss, and attempts to remove the superior temporal gyral lesion were abandoned. The bone flap was left out. A post-

From the Department of Surgery, Division of Neurosurgery, The Hospital for Sick Children, The University of Toronto, Toronto, Ontario, Canada.

Received January 12, 2009. Final Revisions Submitted February 27, 2009. Correspondence to: James T. Rutka, The Hospital for Sick Children, Department of Surgery, Division of Neurosurgery, Suite 1503, 555 University Avenue, Toronto, Ontario, M5G 1X8, Canada. 

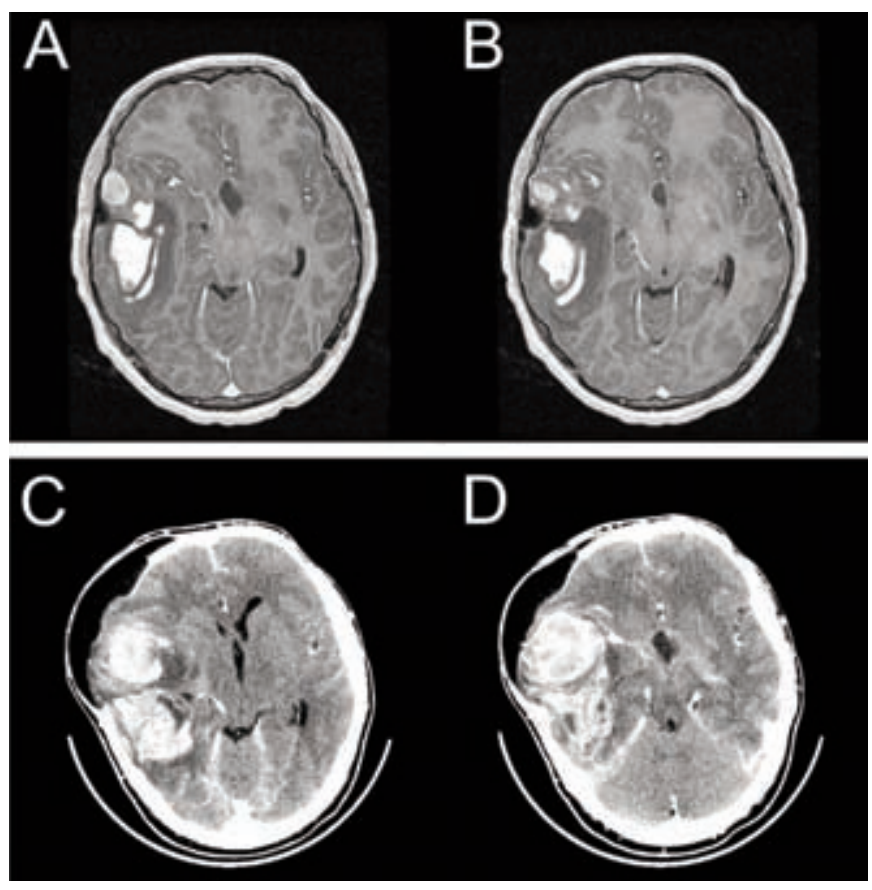

Figure 1: A/B. Axial T2-weighted MRI depicting a right temporal intracerebral hemorrhage with midline shift remote from a chiasmatic tumor. There is also a nodular pouch like lesion in the superficial temporal region with minimal contrast enhancement. C/D. Axial CT with contrast 25 days after initial treatment reveals a rapidly enlarging right temporal hemorrhagic lesion with associated parenchymal hemorrhage. There is also increased subfalcine herniation and a subgaleal fluid collection at the site of the craniectomy.

operative angiogram did not reveal a vascular lesion. The patient was discharged home eight days after admission in good condition with plans to replace the bone flap in eight weeks.

Seventeen days after discharge, the patient returned to the hospital with sudden onset of severe headache. The patient was alert and oriented with a left facial palsy and left hemiparesis. His craniectomy site was now bulging. An urgent CT revealed a rapidly enlarging right temporal hemorrhagic lesion with associated parenchymal hemorrhage (Figure 1C-D). The patient was taken back to the operating room for evacuation of the new hematoma, and surrounding brain tissue including the right superior temporal gyral lesion. He tolerated this procedure well, but required a ventriculoperitoneal shunt for a cerebrospinal fluid (CSF) disturbance in the post-operative period. The neuropathology of the submitted specimens revealed a cellular tumour composed of elongated cells having an abundant eosinophilic cytoplasm with centrally located and blunt-end, cigar-shaped nuclei. The tumour cells merged with the blood vessel wall and were arranged in a fascicular growth pattern in which the bundles intersected at right angles. The tumour showed high mitotic activity and recent hemorrhage. By in situ hybridization analysis, Epstein Barr infection was excluded. A diagnosis of intracranial leiomyo-sarcoma was made (Figure 2).
The patient was discharged home in good condition without new neurological deficit, and returned six months later for bone flap replacement. Staging studies, including a spinal MRI, chest, and abdominal CTs, showed no tumour elsewhere making the diagnosis of metastatic leiomyosarcaroma unlikely. He received postoperative chemotherapy with two cycles of ICE (ifosfamide, carboplatin, and etoposide) and then proceeded to focal radiation using intensity modulated radiation therapy to the right frontotemporal region. He received concomitant oral etoposide during radiation therapy for two cycles, and this was followed by four additional cycles of ICE chemotherapy. He has been well without evidence of tumour recurrence at two years (Figure 3).

\section{DISCUSSION}

Neurofibromatosis type 1 is a condition that represents a major risk factor for malignancy, particularly malignant peripheral nerve sheath tumours, gliomas and leukemias. The patient described in this case report represents a typical pediatric NF1 patient. The patient was followed closely and treated for an optic chiasmatic glioma in early childhood. Surveillance studies over time failed to demonstrate the development of a new intracranial mass lesion. The acute onset of headache and vomiting was the primary indication of an underlying structural abnormality in the brain.

Neurofibromatosis type 1 has been classified as an inherited predisposition syndrome to cancer. Both children and adults are at risk of developing a variety of benign and malignant tumors ${ }^{7}$. Fortunately the most common tumours found in these patients are benign, usually neurofibromas and optic gliomas ${ }^{1}$. Patients with NF1 have a three to five times greater risk of developing a malignancy than the general population ${ }^{4}$. Both CNS and nonCNS malignant tumours are associated with a higher frequency in $\mathrm{NF}^{8}{ }^{8}$. Associated non-CNS tumours reported with a higher than expected incidence include pheochromocytoma, Wilm's tumour, rhabdomyosarcoma, soft-tissue sarcoma, and leukemia ${ }^{3,9,10}$.

Intracranial lesions of the CNS, particularly unidentified bright objects, and gliomas are typically followed with serial MRI studies in patients with NF1. Optic pathway gliomas are found in approximately $15 \%$ of NF1 patients ${ }^{11}$. Most children are asymptomatic, but they can manifest with symptoms of decreased visual acuity, visual field defects, or precocious puberty $^{12}$. Aside from optic gliomas, astrocytomas of the cerebrum, brainstem, and cerebellum are the most common intracranial tumours encountered in $\mathrm{NF}^{3,13}$. In addition to these tumours, many reports of other intracranial tumours occurring in patients with NF1 can be found in the literature. Some of these intracranial tumours include medulloblastoma, dysembryoplastic neuroepethelial tumour, neurocytoma and soft-tissue sarcomas ${ }^{3}$.

Soft-tissue sarcomas represent about $8 \%$ of all malignant tumours of children and adolescents with $\mathrm{NF} 1^{14}$. The most common neurogenic sarcoma, the malignant peripheral nerve sheath tumour (MPNST) occurs in upwards of $10 \%$ of NF1 patients ${ }^{15}$. Malignant peripheral nerve sheath tumours contribute significantly to the reduced life-span of NF1-patients. Nonneurogenic sarcomas like rhab-domyosarcoma accounts for about half of soft tissue sarcoma cases ${ }^{14}$.

Soft tissue sarcomas of the central nervous system are uncommon. The vast majority of these cases are secondary 


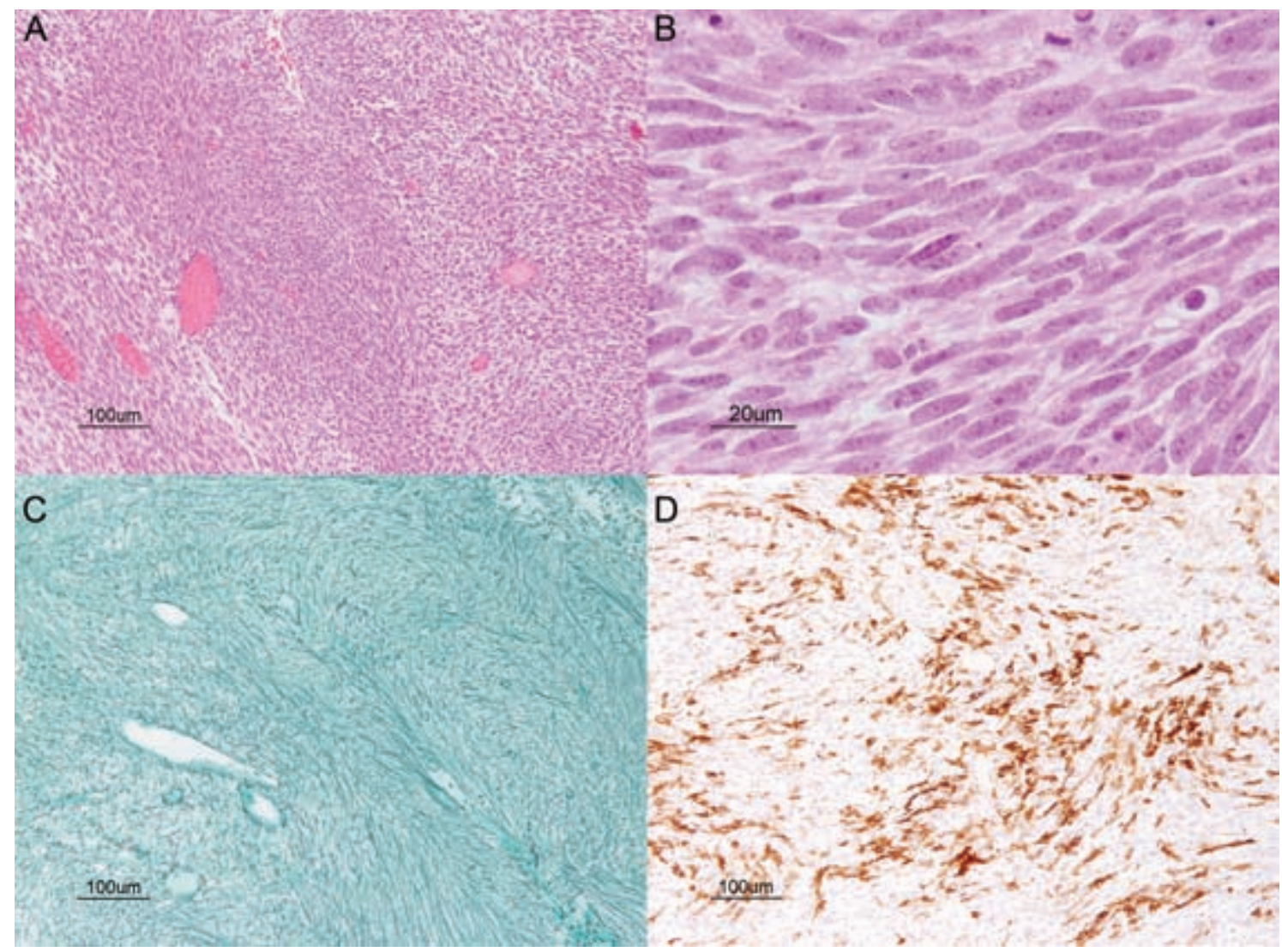

Figure 2: Histological features of the leiomyosarcoma. A. Low power H\&E showing the intersecting fascicular architecture. The tumour cells have cytoplasm ranging from eosinophilic to clear. B. Cytologic features of leiomyosarcoma on H\&E showing the eosinophilic cytoplasm and blunt-ended I "cigar-shaped" nuclei. C. Abundant reticulin deposition, typical of sarcomas, is demonstrated with the reticulin stain. D. The tumour cells are immunopositive for smooth muscle actin. Scale bars represent $100 \mu \mathrm{m}$ in panels $A, C \& D$ and $20 \mu \mathrm{m}$ in panel $B$.

tumours spread from other primary sites. Primary intracranial sarcomas are especially rare ${ }^{16}$. Sporadic cases of intracranial rhabdomyosarcoma, leiomyoma, medulloblastoma with smooth muscle differentiation and leiomyosarcoma have been reported $^{3,17,18}$. These intracranial sarcomas are thought to have a leptomeningeal as well as vascular origin. Many have found to arise from the dura matter and cerebral vascular epithelium ${ }^{19}$.

Soft tissue sarcomas are commonly associated with NF1. Non-CNS rhabdomyosarcoma is the most frequent of these sarcomas. Leiomyosarcoma is another soft-tissue sarcoma found in NF1, but typically it arises from the abdominal cavity ${ }^{20-22}$. Other cases of hepatic and bladder leiomyosarcoma in NF1 patients have also been reported ${ }^{23,24}$. To our knowledge, the child we present here represents the first patient with NF1 and an intracranial leiomyosarcoma. Interestingly, in non-NF1 patients with malignant mesenchymal tumours, H-ras-1 mutations have been found in malignant fibrous histiocytoma, leiomyosarcoma and embryonal rhabdomyosarcoma ${ }^{25}$. As the NF1 gene encodes a tumour suppressor which inactivates ras, a possible underlying genetic mechanism is conceivable in the case we report here.

Intracranial leiomyosarcomas are exceedingly rare, the majority of which represent metastatic disease ${ }^{11}$. To date, none of the reported cases of primary cerebral leiomyosarcoma have been associated with patients with NF1. Of the reported cases of intracranial leiomysoarcomas, many have been observed in immunocompromised patients. The association of these neoplasms with AIDS patients, post-transplantaion patients, and patients undergoing radiation therapy has been well documented $^{26,27}$. Many of these cases are associated with Epstein-Barr virus (EBV) infections prior to the onset of tumorigenesis ${ }^{27}$. The patient in our case was likely immunocompromised during his chemotherapy treatments. The pathological report however indicates that the tumour was EBV negative by in situ hybridization studies. There are case reports of EBV-negative intracranial leiomyosarcomas in a 13-year-old boy and 26-year-old $\operatorname{man}^{28,29}$.

The available data on NF1 and the pathogenesis of leiomyosarcomas suggest several possible mechanisms that might have contributed to the development of this rare tumour in this patient. Some of the possible pathological processes include: 1) De novo intracranial leiomyosarcoma formation independent of NF1; 2) intracranial leiomyosarcoma associated with NF1;3) intracranial leiomyosarcoma secondary to prolonged immunosuppression from chemotherapy, and 4) a chemotherapy-induced 

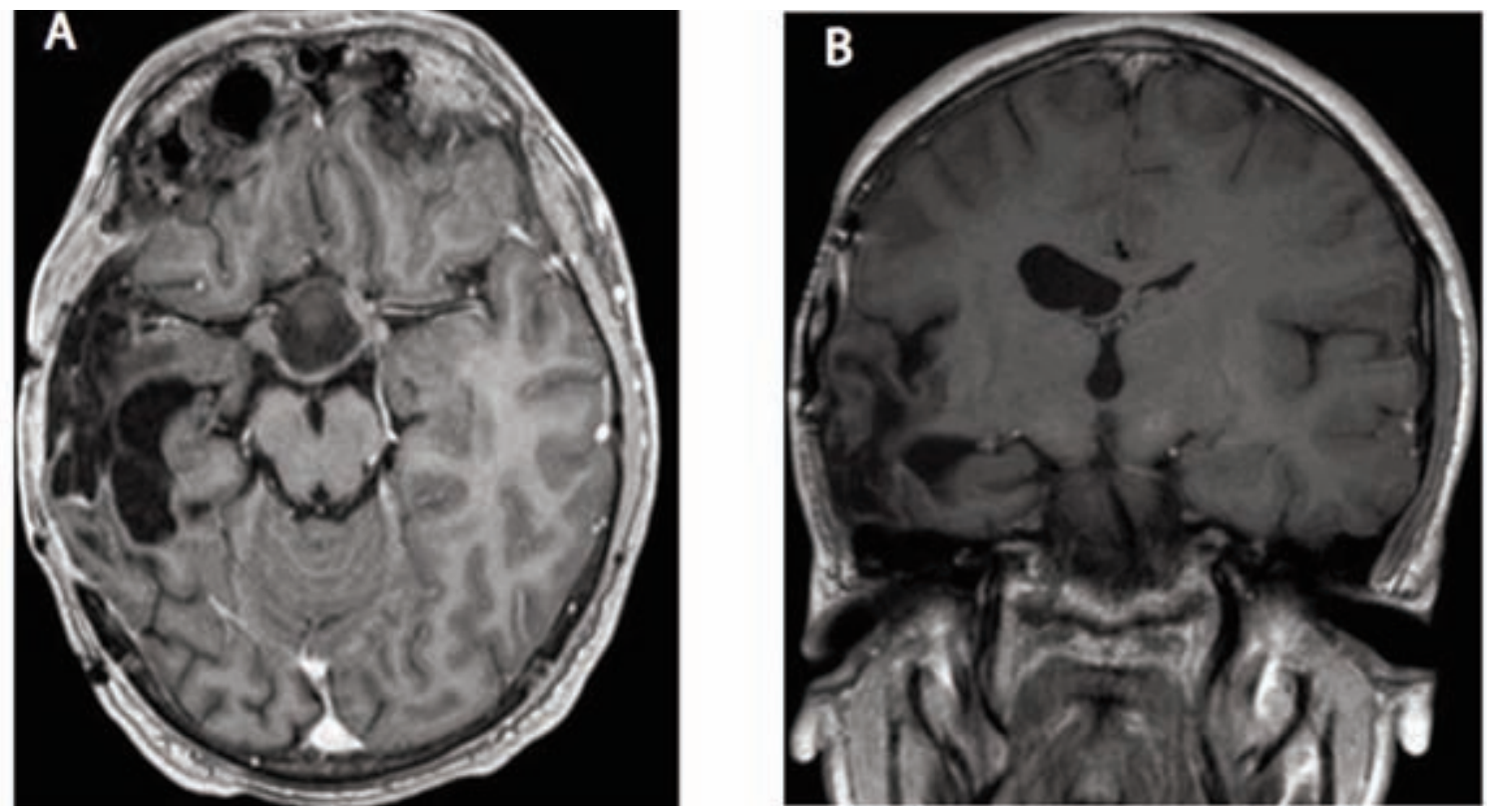

Figure 3: Follow-up MRI two years after treatment for intracranial leiomyosarcoma. A. Axial MR with contrast shows encephalomalacia and atrophy within the right temporal lobe at the site of the prior hemorrhage and surgery. The central defect within the prior optic chiasmatic glioma is also seen on this image. B. Coronal MR with contrast shows dilatation of the ipsilateral ventricle in addition to the temporal lobe changes. There is no evidence of recurrent leiomyosarcoma.

leiomyosarcoma in a patient with NF-1. Regarding this latter possibility, it is known that chemotherapy is far more potent than radiation therapy at inducing cancers such as leukemias ${ }^{30}$. This is particularly true following treatments with alkylating agents and topoisomerase II inhibitors. As for solid tumours, a causal link has been made between the administration of cyclophosphamide and bladder cancer $^{31}$ in patients treated for non-Hodgkins lymphoma, and between alkylating agents and bone sarcomas in children $^{32}$. There is also evidence for the induction of breast cancers with alkylating agents in patients treated for Hodgkin's lymphoma ${ }^{33}$.

The optimum treatment of the patient with an intracranial leiomyosarcoma includes the administration of sarcoma-based chemotherapy and radiation therapy. The decision to irradiate the brain of a child with NF1 is undertaken with some caution as there have been reports of an increased incidence of vasculopathy and secondary tumours following radiation in this patient population ${ }^{34}$. In addition, the decision to use alkylating agents in the NF1 population should be done with caution because of the increased risk of secondary leukemia. While follow-up is short, at two years our patient is doing well without tumor recurrence or the development of new intracranial tumours.

In summary we present a case of an intracranial leiomyosarcoma in a pediatric patient with NF1. The presence of this soft tissue sarcoma in the intracranial compartment in a child heavily pre-treated with chemotherapy for optic glioma may suggest a pathogenetic mechanism in a patient with an underlying neurogenetic syndrome.

\section{REFERENCES}

1. Matsui I, Tanimura M, Kobayashi N, Sawada T, Nagahara N, Akatsuka J. Neurofibromatosis type 1 and childhood cancer. Cancer. 1993 Nov 1;72(9):2746-54.

2. Xu GF, O'Connell P, Viskochil D, Cawthon R, Robertson M, Culver $\mathrm{M}$, et al. The neurofibromatosis type 1 gene encodes a protein related to GAP. Cell. 1990 Aug 10;62(3):599-608.

3. Korf BR. Malignancy in neurofibromatosis type 1. Oncologist. 2000;5(6):477-85.

4. Cohen BH, Rothner AD. Incidence, types, and management of cancer in patients with neurofibromatosis. Oncology (Williston Park). 1989 Sep;3(9):23-30; discussion 4, 7-8.

5. Listernick R, Charrow J, Gutmann DH. Intracranial gliomas in neurofibromatosis type 1 . Am J Med Genet. 1999 Mar 26;89 (1):38-44.

6. Sorensen SA, Mulvihill JJ, Nielsen A. Long-term follow-up of von Recklinghausen neurofibromatosis. Survival and malignant neoplasms. N Engl J Med. 1986 Apr 17;314(16):1010-5.

7. Bader JL. Neurofibromatosis and cancer. Ann NY Acad Sci. 1986; 486:57-65.

8. Riccardi VM. Von Recklinghausen neurofibromatosis. N Engl J Med. 1981 Dec 31;305(27):1617-27.

9. Side L, Taylor B, Cayouette M, Conner E, Thompson P, Luce M, et al. Homozygous inactivation of the NF1 gene in bone marrow cells from children with neurofibromatosis type 1 and malignant myeloid disorders. N Engl J Med. 1997 Jun 12;336(24):1713-20.

10. Walther MM, Herring J, Enquist E, Keiser HR, Linehan WM. von Recklinghausen's disease and pheochromocytomas. J Urol. 1999 Nov;162(5):1582-6.

11. Lewis RA, Gerson LP, Axelson KA, Riccardi VM, Whitford RP. von Recklinghausen neurofibromatosis. II. Incidence of optic gliomata. Ophthalmology. 1984 Aug;91(8):929-35.

12. Listernick R, Charrow J, Greenwald M, Mets M. Natural history of optic pathway tumors in children with neurofibromatosis type 1: a longitudinal study. J Pediatr. 1994 Jul;125(1):63-6. 
13. Pollack IF, Mulvihill JJ. Special issues in the management of gliomas in children with neurofibromatosis 1. J Neurooncol. 1996 May-Jun;28(2-3):257-68.

14. Bien E, Stachowicz-Stencel T, Sierota D, Polczynska K, Szolkiewicz A, Adamkiewicz-Frozynska E, et al. Sarcomas in children with neurofibromatosis type 1-poor prognosis despite aggressive combined therapy in four patients treated in a single oncological institution. Childs Nerv Syst. 2007 Oct;23(10): 1147-53.

15. Evans DG, Baser ME, McGaughran J, Sharif S, Howard E, Moran A. Malignant peripheral nerve sheath tumours in neurofibromatosis 1. J Med Genet. 2002 May;39(5):311-4.

16. Paulus W, Slowik F, Jellinger K. Primary intracranial sarcomas: histopathological features of 19 cases. Histopathology. 1991 May;18(5):395-402.

17. Hope DG, Mulvihill JJ. Malignancy in neurofibromatosis. Adv Neurol. 1981;29:33-56.

18. Riccardi VM. Histogenesis control genes and neurofibromatosis 1. Eur J Pediatr. 2000 Jul;159(7):475-6.

19. Lee TT, Page LK. Primary cerebral leiomyosarcoma. Clin Neurol Neurosurg. 1997 Aug;99(3):210-2.

20. Bernardis V, Sorrentino D, Snidero D, Avellini C, Paduano R, Beltrami CA, et al. Intestinal leiomyosarcoma and gastroparesis associated with von Recklinghausen's disease. Digestion. 1999 Jan-Feb;60(1):82-5.

21. Ishizaki Y, Tada Y, Ishida T, Bandai Y, Idezuki Y, Hitoshi N, et al. Leiomyosarcoma of the small intestine associated with von Recklinghausen's disease: report of a case. Surgery. 1992 Jun;111(6):706-10

22. Kawano N, Ryu M, Kinoshita T, Konishi M, Iwasak M, Furuse J, et al. Segmental resection of the duodenum for treating leiomyosarcoma associated with von Recklinghausen's disease: a case report. Jpn J Clin Oncol. 1995 Jun;25(3):109-12.

23. Maruta K, Sonoda Y, Saigo R, Yoshioka T, Fukunaga H. [A patient with von Recklinghausen's disease associated with polymyositis, asymptomatic pheochromocytoma, and primary hepatic leiomyosarcoma]. Nippon Ronen Igakkai Zasshi. 2004 May; 41(3):339-43.

24. Poleksic S. Leiomyosarcoma of urinary bladder in von Recklinghausen's neurofibromatosis. Urology. 1977 Oct;10(4): 341-2.
25. Watanabe T, Sakamoto A, Tamiya S, Oda Y, Masuda K, Tsuneyoshi M. H-ras-1 point mutation in malignant peripheral nerve sheath tumors: polymerase chain reaction restriction fragment length polymorphism analysis and direct sequencing from paraffinembedded tissues. Int J Mol Med. 2000 Jun;5(6):605-8.

26. Bejjani GK, Stopak B, Schwartz A, Santi R. Primary dural leiomyosarcoma in a patient infected with human immunodeficiency virus: case report. Neurosurgery. 1999 Jan;44(1): 199-202.

27. Brown HG, Burger PC, Olivi A, Sills AK, Barditch-Crovo PA, Lee RR. Intracranial leiomyosarcoma in a patient with AIDS. Neuroradiology. 1999 Jan;41(1):35-9.

28. Eckhardt BP, Brandner S, Zollikofer CL, Wentz KU. Primary cerebral leiomyosarcoma in a child. Pediatr Radiol. 2004 Jun; 34(6):495-8.

29. Hussain S, Nanda A, Fowler M, Ampil FL, Burton GV. Primary intracranial leiomyosarcoma: report of a case and review of the literature. Sarcoma. 2006;2006:52140.

30. Van Leeuwen FE, Travis LB. Second Cancers. In: De Vita VT, Hellman S, Rosenberg S, editors. Cancer: Principles and Practice of Oncology. 7th ed. Philadelphia: Lilppincott Williams and Wilkins; 2005. p. 2575-602.

31. Travis LB, Curtis RE, Glimelius B, Holowaty EJ, Van Leeuwen FE, Lynch CF. Bladder and kidney cancer following cyclophosphamide therapy for non-Hodgkin's lymphoma. JNCI. 1995;87:524.

32. Hawkins MM, Wilson LM, Burton HS, Potok MH, Winter DL, Marsden HB, et al. Radiotherapy, alkylating agents, and risk of bone cancer after childhood cancer. J Natl Cancer Inst. 1996; 88:270.

33. Travis LB, Hill DA, Dores GM, Gospodarowics M, Van Leeuwen FE, Holowaty E, et al. Breast cancer following radiotherapy and chemotherapy among young women with Hodgkin disease. JAMA. 2003;290:465.

34. Sharif S, Ferner R, Birch JM, Gillespie JE, Gattarnaneni HR, Baser $\mathrm{ME}$, et al. Second primary tumors in neurofibromatosis 1 patients treated for optic glioma: substantial risks after radiotherapy. J Clin Oncol. 2006 Jun 1;24(16):2570-5. 